\title{
DOMAINS OF SAFETY
}

It is considered that providing safety in universal dimension is exclusively responsibility of a public authority and the authority is fully responsible for efficient implementation of systems concerned with it. In reality, there is no prospect of not having incidents and therefore, there is no absolute safety. If such ideas exist anywhere, they are only theoretical concepts. Safety is a condition of the surroundings and natural environment of a local community. The condition level is defined by the degree of existing risk in that community. The risk is ubiquitous and inevitable as it exists in nature and civilian space. So the local governing body must decide what level of risk it is able to accept.

Safety includes a wide range of undertakings be realized in order to provide security in all areas of concern in the state. Therefore, safety is the result of activities of different institutions, services, organizations, and also individual human being, its closest surroundings, local and central authorities.

Every day we are notify of tragic events which means that our life is filled with incidents dangerous for us. Terrorist attacks, natural disasters, technical damages, plane crashes, or road accidents constitute a background of our lives. Breaking one's leg on a slippery surface, thefts, attacks, drowning, or spine injuries after jumping to water in a wrong place, accidents at work or on holidays are just examples of those unwilling events that can happen for everyone. Flooding, damages caused by gales, terrorist attacks are undoubted too. The numerous above examples clearly show that unwilling events vary greatly in their causes, character, results, social, political and economic context as well as individual realm. But no matter how varied they are, there is one common feature that can be described as:

All unwilling events disturb development and existence of individuals, local communities, or even the whole societies and in extreme examples they even make their survival impossible.

This universal feature has crucial influence on perception of safety by most people. It is thought that safety has universal character and can be provided unconditionally, with no importance of what is being secured. Safety of the state is perceived as an "umbrella" that can cover everyone and everything but divided on smaller (local community) and the smallest (individual) parts. Thus, the concept of safety is understood as a lack of unwilling events and, in case of their appearance, causing unimportant results (safety equals lack of threats). But there is no such situation. In reality, there is no prospect of not having incidents and therefore, there is no absolute security. If such ideas exist anywhere, they are only theoretical concepts. Safety (an individual or a state), as well as all connected actions, are often faced with identical requirements, no matter who they concern and what the character of the unwilling event is. It is believed that providing safety in universal dimension is exclusively a responsibility of a public authority and the authority is fully responsible for efficient implementation of response systems.
The problem is worth closer consideration. Let's analyze a road accident where a pedestrian is a victim. He or she crossed a street when the red light was on, straight in front of a correctly driven car. In this case, the pedestrian is found guilty. The red light did not protect him against the accident. The question is if the authorities responsible for safety on roads had done everything in order to provide it. The answer is yes as the red light is a sufficient means of providing safety when crossing a street. Even though, the accident happened. Decision to cross the street was made by the pedestrian himself or herself with no respect to the principles. This is an important moment in our considerations. The pedestrian took on himself or herself the risk of collision with no regard to safety measures employed, like traffic lights, which in this case had a supportive character. Thus, people responsible for safety on roads can only support it and their responsibility does not have and cannot have absolute character. Here, full responsibility is on the pedestrian. That is how it is. Such individual decisions, connected with our own safety, are numerous and examples can be many. On the one hand, there are individual decisions that may cause threat and protection against it and on the other, those decisions can be supported but support is a key word here. There are areas, or better to say, an individual safety domains to which external access is denied. Generalizing the above considerations a following rule can be formulated:

An individual area of a man's actions that may cause a threat or protect against it and that is dependent only on his/her free decision constitutes an individual safety domain (ISD).

An important feature of an individual safety domain is lack of outside influence including external safety systems which play only supportive role in decision making process. Support, in case of the individual safety domain, brings the best effects by promoting awareness of threats, i.e. by education. The education can be included into activities connected with safety system functioning. Long term

\footnotetext{
* Jerzy M. Wolanin

The Main School of Fire Service, Slowackiego 52/54, 01-629Warsaw, Poland, E-mail: Jerzy.Wolanin@sgsp.edu.pl
} 


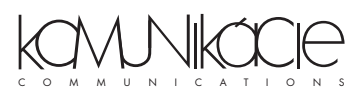

investment in education on safety is the most effective form of supporting safety in the case of ISD.

It is worth considering whether there are other domains of safety. It is known that exposure to threats is not often connected with individual decisions only. In case of sickness or other misfortune we receive help from our family. Building up a surrounding with our neighbour we constitute an element of safety system, together with other functions that the surrounding plays. One can rely on their help. Many decisions, connected with the possibility of threat occurrence, are made within this micro - community (family or neighbourhood). Those decisions, as in a previously mentioned example, are of supportive character and do not provide absolute safety. In this case the following definition can be formulated:

An area of unconstrained activity within a given micro community capable of creating a threat or protecting against it constitutes a micro - community safety domain (MSD).

This domain has also limited access for external safety systems. Although, in some cases we can have direct influence on it. The possibility of a house being robbed is one of them. In order to prevent it security is provided. The possibility of hiring security teams is an element of safety system that exists outside of MSD On the other hand, police force is responsible for fighting against this type of threats, acting within safety system organized by a state. Members of micro - community have a choice then, either to relay on police protection or provide individual protection for a house by hiring security. In the second case, the risk of being robbed is much lower. Here, a phenomenon of micro - community safety domain expansion into a state safety domain of a (SSD) occurs. From the above considered example results a fundamental feature of all domains: safety domains do not have strict boundaries. We can change them, i.e. expand or shrink them according to efficiency of the other domains. Hiring security teams has a number of advantages. It increases safety of micro - community members at the same time decreasing state budget expenses. For instance, police forces do not have to dispatch patrols into protected areas too often or even at all. In this case, transformation expenses of micro community safety domain (MSD) into state safety domain (SSD) are covered by a micro - community.

A domain of safety that covers a wider concept than the domain of micro - community safety is the local safety domain, which can be defined as follows:

An area of unconstrained activity within a given local community capable of creating a threat or preventing it constitutes a domain of local safety (LSD).

It is a highly interesting domain (LSD) that influence al other... within this one. Different concepts i.e. theoretical, political, social, organizational, etc. collide here with the problem of other domains influence on LSD. Thus, some of its constant and interesting features shall be described here. Historical experience of democratic countries shows that this domain is the basic one influencing in real safety in a state as well as citizens' feeling of safety. The stronger external connections of a local community are the greatest expansion of LSD on a state safety domain and the more effective protection against local threats. It is connected with better self-organization of this community, which is similar to previously mentioned self - organization of a micro - community. It influences its greater activity concerning risk management on a given area and consequently decreases in number of claims. This in turn leads to lowering public money expenditure. An important role in self - organization of a local community and building expansive LSD is education of society. Replacing claims with an active attitude allows not only for preventing unwilling events but it contributes to support state services during a catastrophe. On a territory of local communities with strong domains of local safety there are no spectators observing rescuers from outside. Also, inhabitants do not expect rescuers to wash their potatoes of mud as a part of flood results removal activities. These simple examples show the importance of citizens' awareness concerning threats in effective rescue actions.

There is no doubt that facing some threats, their scale and results they may cause, even the most developed local safety domain is not sufficient. Then, a state safety domain (SSD) marks its influence. This domain is generally based on central safety management system. Its role is to support other domains. As it was shown previously, some domains are "impermeable" for a state safety domain, especially of an individual safety domain.

An area of ruler decisions of state authority organs in shaping state's safety policy and their activities providing safety constitutes essence of the domain of a state safety.

As it was mentioned above, providing safety to citizens has no absolute character. According to a domain kind, the influence of the state safety domain is varied. Starting with lack of direct influence on safety area in case of an individual safety domain to complete state of providing safety in case of external and internal threats.

Safety then is not a universal and homogenous being. Its character is rather of varied and grained structure whose basic elements are domains. Domains differ from one another by the scale of interaction but also a level of autonomy in respect to one another. Subsequent domains, starting with the individual one, are more advanced complexity. That, in turn, requires different tools used in safety management. Domains are natural reflection of safety nature and all protecting systems should be connected with it and based on it. The best results are achieved by building systems according to "upwards" rule. However, every higher level should support the lower one. With regard to possible conflicts of legal and authoritative character, those elements of safety system that define boundaries of every domain should be precisely defined. Taking into consideration autonomy of domains as well as freedom to start activities within each of them, providing complete safety is impossible in its nature. 